\title{
Unexpected allergic reactions to food, a prospective study
}

\author{
Anouska Michelsen-Huisman ${ }^{1 *}$, Harmieke Os-Medendorp ${ }^{1}$, Astrid Versluis ${ }^{1}$, Astrid Kruizinga ${ }^{2}$, \\ Jacqueline Castenmiller ${ }^{3}$, Hub Noteborn ${ }^{3}$, Geert Houben ${ }^{2}$, André Knulst ${ }^{1}$ \\ From Food Allergy and Anaphylaxis Meeting 2014 \\ Dublin, Ireland. 9-11 October 2014
}

\section{Background}

Severe reactions and even fatalities occur in patients with food allergy, due to unexpected allergen exposure, but frequency data are scarce. The aim of this study is to investigate the frequency, severity and causes of unexpected allergic reactions to food in adults diagnosed with food allergy.

\section{Methods}

A prospective cohort study is carried out starting January 2012. A total of 180 adult patients with a physicianconfirmed diagnosis of food allergy will be included and followed during one year. Outcome measures are frequency, severity and causes of unexpected reactions. Participants complete an online questionnaire after every unexpected reaction and send in the culprit product including the food label. The product is analyzed for suspected allergens.

\section{Results}

Until now 152 patients (mean age=36 years (range 19-71), $70 \%$ female) have been included. The mean number of foods for which the patients are allergic was 5.5 (range 1-17). A total of 118 unexpected reactions were reported during the mean follow-up period of 9.7 months. Ninetyseven patients $(64 \%)$ had no reactions, twenty-nine (19\%) reported one reaction and twenty-six (17\%) patients reported more than one reaction (range 2-11). Severity of these reactions was Muller 0: $18 \%$, Muller I: $26 \%$, Muller II: 27\%, Muller III: 23\% and Muller IV: 6\%.

Preliminary results show that $44 \%(n=52)$ of the unexpected reactions were caused by pre-packaged products, $23 \%(n=27)$ by composite meals outdoors, for example at a friends' or relatives home, at school or in a restaurant, $17 \%(n=20)$ by fresh products, $8 \%(n=9)$ by composite meals at home and $8 \%(n=10)$ of the reactions took place abroad.

Main causes of unexpected reactions were labelling issues and risk taking behaviour of some patients. Fortyseven products were sent in to be analyzed. In one third of the products analyzed, the suspected allergen was detected.

\section{Conclusions}

$36 \%$ of the participants reported at least one unexpected allergic reaction. The mean number of reactions was 1 per person per year; reactions were mostly moderate to severe. Most reactions occurred after consuming pre-packaged foods. Labelling issues were frequently involved.

\section{Authors' details \\ ${ }^{1}$ UMC Utrecht, Utrecht, The Netherlands. ${ }^{2}$ Netherlands Organisation for Applied Scientific Research (TNO), Zeist, The Netherlands. ${ }^{3}$ Netherlands Food and Consumer Product Safety Authority (NWWA), Utrecht, The Netherlands.}

Published: 30 March 2015

doi:10.1186/2045-7022-5-S3-P149

Cite this article as: Michelsen-Huisman et al.: Unexpected allergic reactions to food, a prospective study. Clinical and Translational Allergy 2015 5(Suppl 3):P149.

'UMC Utrecht, Utrecht, The Netherlands

Full list of author information is available at the end of the article 